\title{
Development of an RAPD-based SCAR marker for smut disease resistance in commercial sugarcane cultivars of Pakistan
}

\section{Mehwish Khan ${ }^{a}$, Yong-Bao Pan ${ }^{b^{*}}$, Javed Iqbal ${ }^{a}$}

${ }^{a}$ School of Biological Sciences, Quaid-e-Azam campus, University of the Punjab, Lahore, Pakistan

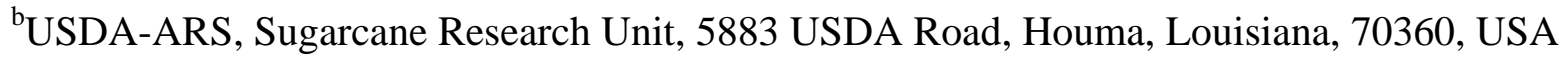
*Corresponding authors: E-mail: YongBao.Pan@ars.usda.gov; javediqbal1942@yahoo.com

\begin{abstract}
A 300-bp RAPD-derived Sequence Characterized Amplified Region (SCAR) marker linked with resistance to sugarcane smut disease was developed. Bulked segregant analysis and RAPD were conducted using 480 random decamers in the initial screening of 12 sugarcane cultivars (two completely smut resistant, two completely smut susceptible, four moderately smut resistant, and four moderately smut susceptible). Eighty-four of these primers proved to be polymorphic while only one (B17) produced a reproducible polymorphic fragment, which appeared to co-segregate in repulsion with sugarcane smut resistance. A 300-bp B1SM-F/B1SM-R SCAR marker was designed based on the sequence alignment of the B17 products. Testing of this SCAR marker on these 12 cultivars confirmed its specificity on two completely and four partially resistant cultivars. Further screening of this SCAR marker on seven additional sugarcane cultivars of Pakistan verified the earlier findings. Therefore, it was deduced that the B1SM-F/B1SM-R SCAR marker is linked with smut resistance trait in sugarcane. NCBI blast of the SCAR marker sequence showed no homology to any of the earlier identified sequences in GenBank. The newly
\end{abstract}


discovered B1SM-F/B1SM-R SCAR marker for sugarcane smut resistance will facilitate sugarcane breeding programs since it can be used for marker-assisted selection in sugarcane.

\section{Keywords}

Sugarcane; Sporisorium scitamineum; Bulked segregant analysis (BSA); Random amplified polymorphic DNA (RAPD); Sequence characterized amplified region (SCAR)

Abbreviations: HR, Highly resistant; R, Resistant; MR, Moderately resistant; S, Susceptible; MR, Moderately susceptible. 


\section{Introduction}

Sugarcane smut, a well-known fungal disease, the causal agent of which is Sporisorium scitamineum (Que et al., 2014), has been a major concern among sugarcane breeders in those countries where the disease is highly prevalent (Croft et al., 2008). The disease was thought to be limited within the confines of Eastern Hemisphere when it was first observed in 1877 in the fields of Natal, South Africa, until it had progressed to Argentina in 1940 (Gillaspie et al., 1983). By 1971, sugarcane smut had made its way to the United States in Hawaii and was later identified in Florida in1978, and since then it has been a subject of great scrutiny and inspection for sugarcane growers around the world (Comstock et al., 1983). The threatening increase in the incidences of smut has affected almost all sugarcane producing countries including Pakistan which happens to be the fifth largest producer of sugarcane in the world (FAO, 2014). According to a survey, the damage caused by smut may account for $39-56 \%$ of yield loss in planted sugarcane crop and 52-73\% in that of ratoon crop (Khan et al., 2009). In one of the studies conducted in Australia, maximum yield loss due to smut in a highly susceptible sugarcane variety Q157 was estimated to be 62\% (Magarey et al., 2010), thereby highlighting the potential risk posed by smut epidemic to non-resistant sugarcane lines.

Control methods have been employed to prevent the spread and recurrence of smut in cultivated cane including hot-water treatment, the use of fungicides (Bailey, 1979) and planting resistant cultivars (Braithwaite et al., 2004). Nonetheless, the varietal response to smut is also dependent on the geographical region, since different pathogenic races of smut are native to different areas of the world (Comstock et al., 1983). In 1976, a second race of smut was uncovered when black whips of smut started appearing on a highly resistant Hawaiian variety H50-7209 (Schenck, 2003). This finding prompted Hawaiian breeders to conduct thorough 
screening of all commercial varieties for resistance against both races of smut (Schenck, 2003). Although a definite account of smut-races and their occurrence is yet to be established, the study is pertinent for selection of smut-resistance in sugarcane breeding programs (Braithwaite et al., 2004).

The deployment of smut resistant varieties has been deemed most lucrative for limiting the damage caused by Sporisorium scitamineum (Sundar et al., 2012). Many endeavors have been made to aid selection and breeding of such cultivars, the Hawaiian variety development program is one such example, in which any variety with susceptibility rating of six or more is debarred from the plan (Comstock et al., 1983; Schenck, 2003). In Louisiana, USA, three years of research involving 18 bi-parental crosses led to the conclusion that the use of susceptible parents has to be reduced in order to enhance the percentage of resistant offspring (Chao et al., 1990). Similarly in Australia, following the smut epiphytotic in 2006, the BSES-CSIRO Variety Improvement Program resolved not to carry out susceptible crosses unless they have increased breeding value (Croft et al., 2008). However, the conventional breeding methods for the selection of resistance trait are rendered less efficient due largely to their time-consuming and laborious nature (Heinze et al., 2001). Therefore, molecular tools and practices for instance, molecular markers come in quite handy in this respect (Srivastava et al., 2012).

Molecular markers offer a highly proficient solution for the selection of desirable traits in breeding programs, as they allow screening of plants at any given time of development irrespective of the abiotic stresses (Ardiel et al., 2002). Of all the techniques currently available, RAPD technology is thought to be the most appropriate for this purpose (Zhang et al., 2013). RAPD markers along with Bulked Segregant Analysis (BSA) (Michelmore et al., 1991) have proven to be exceedingly worthwhile in this regard because both are uncomplicated and cost- 
effective (Yang et al., 2013). Moreover, the method does not require any prior knowledge of DNA sequence (Jiang et al., 2009). Nevertheless, the major drawback to RAPD-PCR is its inability to yield reproducible polymorphism under varying laboratory conditions (Srivastava et al., 2012). One way to overcome the issue is to construct more specific and reliable markers called Sequence Characterized Amplified Regions (SCAR) from RAPD-derived DNA fragments (Dnyaneshwar et al., 2006). In theory, the conversion of RAPD into SCAR represents the development of co-dominant markers from dominant markers so as to avoid lengthy RAPD reactions (Li et al., 2010). The resulting SCAR markers are typical oligonucleotides, used in regular PCR procedures and generally have a high probability of producing polymorphic amplicons (Cheng et al., 2015). The aim of this study was to identify a SCAR marker linked with smut resistance in commercial sugarcane cultivars of Pakistan by utilizing BSA and RAPD techniques.

\section{Materials and methods}

\subsection{Plant Material}

Twelve commercial sugarcane cultivars, characterized on the basis of disease resistance/susceptibility to whip smut were used for this study (Table 1). Seven additional sugarcane cultivars were also used for validating the final outcome of the research (Table 2). The data regarding parental crosses and disease rating was provided by Shakarganj Sugar Research Institute, Jhang. Screening of sugarcane cultivars for disease reaction was done on the scale of 0-30\% for smut (Krishnamma et al., 1999). 


\subsection{Extraction of genomic DNA}

Fresh leaves were excised from each of the total 19 cultivars planted in the fields of School of Biological Sciences (Punjab University, Lahore, Pakistan.). Total genomic DNA isolation was performed using slightly modified CTAB DNA Extraction Protocol (Doyle and Doyle, 1990). For quality analysis of DNA, electrophoresis was performed on $0.8 \%$ agarose gels. The purified DNA was then quantified using NanoDrop spectrophotometer by recording readings at the wavelengths of 260 and $280 \mathrm{~nm}$. Finally, the concentrations of all the DNA samples were normalized to $60 \mathrm{ng} / \mu \mathrm{l}$.

\subsection{Bulked Segregant Analysis and RAPD-PCR}

BSA is a method which allows DNA samples having identical cultivars for a particular trait (i.e., response to smut in this case) to be pooled into one group (Michelmore et al., 1991). Based on their reaction to smut disease, DNA samples from the 12 cultivars were used to create four different bulks, namely, completely resistant (CPSG-437 and CPSG-3481), completely susceptible (SPSG-26 and CSSG-2402), moderately resistant (CP77-401, CPF-237, NSG-59 and HoG-315), and moderately susceptible (CSSG-668, SPSG-79, SPF-241 and HoSG-449). Each bulk contained equal quantities of DNA of the respective cultivars constituting the bulk.

For initial RAPD analysis of the four DNA bulks, 480 arbitrary decamer primers purchased from Bioneer, Alameda, CA, USA (K, L and M series), Bio Basic Inc., Amherst, NY, USA (S-series), and Operon Technologies Inc., Alameda, CA, USA, were utilized. PCRamplification of each DNA bulk was performed with HotStar Taq DNA Polymerase (Qiagen cat\#203207). The reaction mixture of $15 \mu \mathrm{l}$ contained, $2.5 \mu \mathrm{l}$ of 10x HotStar Taq buffer, $1.5 \mathrm{mM}$ of $\mathrm{MgCl}_{2}, 0.2 \mathrm{mM}$ of dNTPs, $0.4 \mu \mathrm{M}$ of primer, 1 unit of HotStar Taq DNA Polymerase and 60 ng of DNA template. Thermocycling was carried out in Gene Amp PCR System 9700 (Applied 
Biosystem, Inc., Foster City, CA, USA) using initial denaturing at $95^{\circ} \mathrm{C}$ for $15 \mathrm{~min}$, followed by 40 cycles of $94^{\circ} \mathrm{C}$ for $2 \mathrm{~min}, 40^{\circ} \mathrm{C}$ for $1 \mathrm{~min}, 72^{\circ} \mathrm{C}$ for $2 \mathrm{~min}$ and finished with final extension at $72^{\circ} \mathrm{C}$ for $10 \mathrm{~min}$. Amplification products were separated on $1 \%$ agarose gel in $1 \mathrm{x}$ TAE bufer, stained with ethidium bromide, and visualized on video imaging system of either Dolphin Gel Documentation System or Kodak gel imaging system. GeneRuler DNA ladder mix (Cat\#SM0331, Fermentas Life Sciences, Burlington, ON, Canada) was run along the amplicons as DNA size marker.

Primers that produced polymorphic DNA fragments among the four DNA bulks were used for RAPD analysis of individual cultivars comprising the bulk. Each reaction was repeated at least three times so as to verify its reproducibility. One primer (B17), which showed a reproducible polymorphism with completely susceptible and moderately susceptible cultivars, was selected for further analysis.

\subsection{Cloning and sequencing of RAPD fragments}

The polymorphic DNA fragments from B17-primed amplification from susceptible and moderately susceptible cultivars were excised from the gel and purified with QIAquick Gel Extraction Kit (Cat\#28704, Qiagen, Germantown, MD, USA). The purified fragments were then cloned into pCR ${ }^{\mathrm{TM}} 4-\mathrm{TOPO}$ vector using TOPO TA Cloning Kit (Cat\# K4575-01, Invitrogen Corp., Carlsbad, CA, USA), according to the given protocol. Transformation was performed by introducing the recombinant plasmids into chemically competent $E$. coli (DH5 $\left.\alpha^{\mathrm{TM}}-\mathrm{T} 1 \mathrm{R}\right)$ cells. Each transformation mix was then plated onto a selective medium. At least 12 white colonies were selected from each plate and cultured individually in LB broth (supplemented with Ampicillin $100 \mathrm{mg} / \mathrm{L}$ ) at $37^{\circ} \mathrm{C}$ for approximately 10 hours. The presence of insert in the clones was verified by colony-PCR with M13 universal primers. Cultures of the confirmed clones were 
sent for sequencing in MCLAB (South San Francisco, CA, USA). After sequencing, data analysis and sequence alignments were accomplished using the software program DNAMAN ${ }^{\circledR}$ version 5.2.9 (Lynnon BioSoft, San Ramon, CA, USA).

\subsection{Designing SCAR marker and SCAR analysis}

Initially, a pair of specific oligonucleotides (B1F/B1R SCAR marker) was designed based on the sequences of RAPD amplicons, but the marker failed to generate polymorphism among the four groups of resistant, moderately resistant, susceptible and moderately susceptible cultivars. This marker did amplify a 400 bp monomorphic product from all the individuals constituting the four bulks (resistant, moderately resistant, susceptible and moderately susceptible). These 400-bp monomorphic bands were gel purified, cloned into the pCR ${ }^{\mathrm{TM}} 4-\mathrm{TOPO}$ vector and sequenced commercially by the MCLAB (South San Francisco, CA, USA). Both DNAMAN ${ }^{\circledR}$ and MegAlign software version 5.00 (DNAStar, Madison, WI, USA) were used to achieve multiple sequence alignment of the sequences isolated from completely resistant, completely susceptible, moderately resistant and moderately susceptible cultivars. On the basis of the sequence comparison, another pair of oligonucleotides was synthesized by Integrated DNA Technology, Inc. (Coralville, IA, USA). The names of the primer pair and oligonucleotide sequences were: B1SM-F (5' AGGGAACGAGGTGGGGAGCG) and B1SM-R (5'

\section{TGAGAATAATTAGTCATGCTGTGCA).}

The SCAR amplifications were carried out in $50 \mu 1$ of PCR mixture, prepared with $60 \mathrm{ng}$ of template DNA, 1x Hot Start PCR Buffer [200 mM Tris-HCl (pH 8.3 at 25ㄷ), $200 \mathrm{mM} \mathrm{KCl,}$ $\left.50 \mathrm{mM}(\mathrm{NH} 4)_{2} \mathrm{SO}_{4}\right], 3 \mathrm{mM} \mathrm{MgCl} 2,100 \mu \mathrm{M}$ dNTPs, $0.4 \mu \mathrm{M}$ of each primer (B1SM-F \& B1SMR), and 1 unit of Hot Start Taq DNA Polymerase (Fermentas cat\# EP0601). The amplifications were performed in DNA Thermocycler Eppendorf Master Cycler AG22331 and the thermal 
cycling profile was optimized as: $15 \mathrm{~min}$ at $95^{\circ} \mathrm{C}$, followed by 40 cycles of 2 min at $94^{\circ} \mathrm{C}, 1 \mathrm{~min}$ at $64^{\circ} \mathrm{C}, 2 \mathrm{~min}$ at $72^{\circ} \mathrm{C}$, and finally, the samples were subjected to an extension step of $10 \mathrm{~min}$ at $72^{\circ} \mathrm{C}$. PCR products as well as the DNA ladder (Fermentas cat\#SM0331) were resolved by electrophoresis on $1 \%$ agarose, 1 xTAE gel. Gels were stained with $0.5 \mu \mathrm{g} / \mathrm{ml}$ ethidium bromide and were viewed and documented using Dolphin-DOC gel documentation system (WEALTEC). The SCAR primer products of $300 \mathrm{bp}$ were then excised from gel, purified using GeneJET gel extraction kit (Fermentas cat\#K0691), cloned into pTZ57R/T vector using Ins TA Clone PCR Cloning Kit (Fermentas cat\#K1213) and sequenced by Macrogen Inc. (Geumcheon-gu, Seoul, Korea).

Finally, the designed SCAR primers were used for amplifying the DNA samples of seven more Pakistani sugarcane cultivars (HoSG-31, CPF-251, HoTh-1821, CPF-252, CPF-249, CSSG-32, and HSF-240).

\section{Results}

\subsection{Screening of sugarcane cultivars with Bulked Segregant Analysis}

After screening 480 random decamers with the four DNA bulks (resistant, moderately resistant, susceptible and moderately susceptible), 84 primers (17.5\%) that showed reproducible polymorphism were selected and used to amplify individual cultivars constituting each bulk. With the exception of primer B17 (5'AGGGAACGAG), the rest of the primers were either completely unable to reproduce the polymorphic bands with the individual DNA samples or failed to amplify their respective products from a significant number of bulk members. Primer B17 yielded a predominant 400-bp polymorphic product from completely susceptible and moderately susceptible bulk (Fig.1) and completely susceptible and moderately susceptible 
cultivars (Fig. 2). On the other hand, the same primer amplified only monomorphic bands with completely resistant bulk, moderately resistant bulk, completely resistant individuals, and moderately susceptible individuals (Figs. 1 and 2). The polymorphic band was gel purified, cloned into a cloning vector, transformed into $E$. coli, and sequenced finally.

\subsection{SCAR marker analysis}

In order to create a reliable marker for susceptible cultivars, the sequence of the 400-bp DNA fragment from the bulked segregant analysis was used for further designing a pair of specific primers (B1-F/ B1-R); however, these primers also primed the amplification of similarly sized amplicons from individuals of all four groups of cultivars (Fig. 3).

The PCR products from all cultivars that were either completely resistant, completely susceptible, moderately resistant, or moderately susceptible were excised, cloned, sequenced, and submitted to the NCBI/GenBank databases (Accession numbers: KX611612, KX611613, KX611614, KX611615, KX611616, KХ611617, KХ611618, KХ611619, KХ611620, KХ611621, KX611622 and KX611623). Multiple sequence alignment analysis revealed some nucleotide differences among different cultivars. Based on these sequence variations, a number of primers were designed and synthesized. After several trials, one pair of primers effectively yielded a single PCR product of 300 bp only with completely resistant and moderately resistant cultivars (Figs. 4 and 5).These 300-bp fragments were then gel-extracted, cloned, sequenced, and accessioned to NCBI/GenBank databases (Accession numbers: KX641242, KX641246, KX641251, KX641254, KX641256 and KX641258). This particular primer pair consisted of a forward primer B1SM-F (5'AGGGAACGAGGTGGGGAGCG) and a reverse primer B1SM-R (5'TGAGAATAATTAGTCATGCTGTGCA). The reverse primer was designed to encompass the difference of 10 nucleotides (with eight deletions and two transversions, i.e. T-G and G-A) 
between resistant and susceptible cultivars (Fig. 6), while the forward primer was complementary to a homologous sequence between the two major cultivars.

Later on, the association of the B1SM-F/B1SM-R SCAR marker with the smut disease resistance trait in sugarcane cultivars of Pakistan was confirmed by amplifying the genomic DNA samples from another set of seven cultivars, including HoSG-31(highly resistant to smut), CPF-251, HoTh-1821 and CPF-252 (completely resistant to smut), CPF-249 and CSSG-32 (moderately resistant to smut), and HSF-240 (moderately susceptible to smut). As expected, the desired 300-bp PCR product was amplified from all cultivars, except for HSF-240 (Fig.7).

\section{Discussion}

Molecular markers are considered highly significant for the purpose of studying resistance mechanisms in plants against pathogens (Sundar et al., 2012). RAPD analysis in consort with BSA can provide enormous assistance in identifying DNA sequence variations linked with resistance or susceptibility traits (Ardiel et al., 2002). In the present study, 480 10-mer RAPD primers were used in the initial screening of four DNA bulks of completely resistant, completely susceptible, moderately resistant and moderately susceptible cultivars. Consequently, 84 of those were revealed as polymorphism-generating reproducible primers. Testing of these 84 primers on all individuals within each of the four bulks showed that only one primer, B17, which consistently produced an amplicon of 400 bp from the DNA of all susceptible cultivars. In order to conduct further analysis, the isolation and sequencing of the 400-bp B17 amplicons from all susceptible cultivars was successfully achieved.

Although the term RAPD was first introduced by Williams et al. (1990), but the idea to use it for selection of a particular trait in crops has been floating around for quite some time now 
(Mohan et al., 1997). In one such study, RAPD-based markers linked with SCMV resistance and susceptibility in N11and NCo376, respectively, could be traced back to seven generations that participated in intra- and interspecific crosses which lead to the development of these varieties (Huckett and Botha, 1995). Similarly, as a result of a research conducted in Brazil, three RAPD markers were mapped across an angular leaf spot resistance gene in common beans (Sartorato et al., 2000). Markers derived from RAPD-PCR have also been shown to be linked with zucchini yellow mosaic virus (ZYMV) resistance and powdery mildew resistance in Squash (Brown and Myers, 2001). The same methodology was used in the detection of a short arbitrary DNA sequence linked to a gene conferring resistance against Sporisorium scitamineum in a Chinese sugarcane population (Xu and Chen, 2004). A correlation of RAPD marker with brown rust resistance in sugarcane has also been verified (Muhammad, 2010). Muhammad et al., (2013) effectively exploited the ability of RAPD analysis to detect genetic variations among different cultivars of the same crop and characterized rust resistant and rust susceptible cultivars of sugarcane based on their RAPD amplification profiles (Muhammad et al., 2013).

On the other hand, some researchers have resorted to other techniques, e.g., AFLP (amplified fragment length polymorphism) and cDNA-SRAP (cDNA-sequence-related amplified polymorphism), for the identification of smut resistance markers or genes in the sugarcane genome. In a recent study based on AFLP analysis, two DNA bands or markers were found to be specific to gamma-radiation induced smut-resistant mutants of sugarcane variety GT 54-9 (Esh and Nasr, 2014). The first demonstration of cDNA-SRAP method for the purpose of isolating 19 differentially expressed genes in smut-resistant sugarcane variety NCo376 under smut attack, has also been documented recently (Huang et al., 2015). Hence AFLP and cDNA-SRAP techniques are proven to be quite proficient in determining different aspects of smut resistance mechanism 
employed by sugarcane. However, RAPD analysis is relatively more versatile in its usage in comparison to the two methodologies. Not only does it involve less complicated and shorter operations, but it costs remarkably lesser than AFLP and cDNA-SRAP (Garcia et al., 2004; Wu et al., 2013).

The next step in RAPD-PCR analysis is to validate the marker by ensuring its reproducibility via RAPD to SCAR (sequence characterized amplified regions) conversion, i.e., a more efficacious pair of primers of approximately $15-30 \mathrm{bp}$ in length is designed from the RAPD marker sequence, perfectly capable of yielding dependable results with each amplification (Bhagyawant, 2016). In some cases, the attempts to create a specific primer pair from a RAPD sequence may cause polymorphism to disappear from subsequent amplifications, mostly due to shifting of primer site from mis-pairing RAPD regions to sites of greater sequence homology (Paran and Michelmore, 1993). This may explain the incapacity of our first SCAR marker to reproduce the polymorphism. Therefore in the current work, the stages which lead to the creation of a stable SCAR marker linked to smut resistance in sugarcane involved amplification of all individual DNA samples using a specific primer pair. This primer pair was complementary to the flanking sequences of the B17 RAPD fragment and was able to prime the amplification of a 400bp DNA fragments with all cultivars alike. Followed by sequencing of the resulting amplicons and repeated PCR of the DNA of all cultivars with a variety of primers constructed on the basis of nucleotide differences among the sequences of the 400-bp DNA fragments. The last step was repeated until the designed primers amplified a single 300-bp DNA fragment or SCAR marker from both completely resistant and moderately resistant cultivars. In order to substantiate these findings, an additional set of seven promising and commercial sugarcane cultivars of Pakistan was also screened with the same SCAR marker. The one cultivar that failed to produce the 300- 
bp DNA fragment was in fact, the only cultivar susceptible (moderately) to smut disease among the group of seven. On the basis of this outcome, it was assumed that RAPD marker B17 cosegregated in repulsion with Sporisorium scitamineum resistance.

RAPD-based SCAR markers were used for the first time to tag genes involved in resistance mechanism against downy mildew in lettuce (Paran and Michelmore, 1993). Later on, numerous DNA-based markers were reported to have a close association with disease responses in various plants, e.g., a SCAR marker was identified in relation to Septoria nodorum blotch resistance in durum wheat (Cao et al., 2001). Location of a SCAR marker linked with smut resistance was also mapped to in Barley (Ardiel et al., 2002). Deployment of SCAR marker technique for marker assisted selection in sugarcane is not unprecedented. Studies indicating the role of SCAR markers in characterization of intergenic sugarcane hybrids and SCAR marker linkage to draught tolerance and rust resistance in sugarcane have already been published (Wang et al., 2009; Srivastava et al., 2012; Muhammad, 2010). Interestingly, the presence of a SCAR marker in relation to brown rust resistance in Pakistan's commercial sugarcane cultivars has also been confirmed through similar analytical methods (Muhammad, 2010).

In the present research, nucleotide BLAST analyses of RAPD and SCAR marker products did not show any homology to documented GenBank sequences. Thereby proving that sequence of the marker under discussion does not belong to any identified portion of the sugarcane genome. Owing to the bulky size $(10 \mathrm{~Gb})$ of sugarcane genome and presence of complex polyploidy and aneuploidy, the sugarcane genome sequencing project is still far from completion (Souza et al., 2011). Therefore, the discovery of such unidentified marker sequences linked to a particular trait may contribute minutely to the undertaking of whole genome sequencing. Finally, it can be concluded that unleashing of a SCAR marker sequence which co- 
segregates with smut resistance trait in sugarcane can prove to be of paramount importance to the sugarcane breeding and selection programs.

\section{Conclusion}

In this research, a SCAR marker was designed to tag the smut resistance trait in commercial sugarcane cultivars of Pakistan. Based on this study, it can be deduced that the RAPD technique in concert with BSA is adequately suitable for the identification of genetic sequences linked with disease resistance in sugarcane. Moreover, sequences of the DNA products generated through RAPD can serve as a tremendous source for creating a more specific marker called SCAR. There is also a practical aspect to the development of a SCAR marker reported in this work; it can be used for selection of smut resistance in sugarcane cultivars and hence presents a resourceful tool for sugarcane breeding programs. 


\section{Acknowledgements}

A part of this research work was conducted in Plant Molecular Genetics Laboratory at the School of Biological Sciences, Punjab University, under the supervision of Professor Dr. Javed Iqbal. A major part was carried out in the USDA-ARS, Sugarcane Research Laboratory supervised by Dr. Yong-Bao Pan. The technical help from Dr. Khushi Muhammad and Dr. Shahid Afghan in particular provision of sugarcane cultivars is greatly acknowledged.

\section{Funding}

The financial support was provided by a double grant from the U.S.-Pakistan Science and Technology Cooperation Program.

\section{References}

Ardiel GS, Grewal TS, Deberdt P, Rossnagel BG \& Scoles GJ. Inheritance of resistance to covered smut in Barley and development of a tightly linked SCAR marker. Springer-Ver. 2002. 104:457-454.

Bailey RA. Possibilities for the control of sugarcane smut (Ustilago scitaminea) with fungicides. Proc S Afr Sug Technol Ass. 1979. 53:137-142.

Bhagyawant SS. RAPD-SCAR Markers: an Interface tool for authentication of traits. J Biosci Med. 2016. 4:1-9. 
Braithwaite KS, Bakkeren G, Croft BJ \& Brumbley SM. Genetic variation in a worldwide collection of the sugarcane smut fungus ustilago scitaminea. Proc Aust Soc Sugar Cane Technol. 2004. 26:48-56.

Brown RN \& Myers JR. RAPD Markers Linked to Morphological and Disease Resistance Traits in Squash. Cucurbit Genet Coop Rpt. 2001. 24:91-93.

Cao W, Hughes GR, Ma H \& Dong Z. Identification of molecular markers for resistance to Septoria nodorum blotch in durum wheat. Theor Appl Genet. 2001. 102:551-554.

Chao CP, Hoy JW, Saxton AM \& Martin FA. Heritibility of resistance \& repeatability of clone reactions to sugarcane smut in Louisiana. Phytopathol. 1990. 80:622-626.

Cheng J, Long Y, Khan MA, Wei C, Fu S \& Fu J. Development and significance of RAPD-SCAR markers for the identification of Litchi chinensis Sonn.by improved RAPD amplification and molecular cloning. Electron J Biotechn. 2015. 18: 35-39. Comstock JC, Ferreira SA \& Tew TL. Hawaii's Approach to Control of Sugarcane Smut. Plant Dis. 1983. 67:4-52.

Croft BJ, Berding N, Cox MC \& Bhuiyan S. Breeding smut-resistant sugarcane varieties in Australia - progress and future directions. Proc Aust Soc Sugar Cane Technol. 2008. 30:125-134.

Dnyaneshwar W, Preeti C, Kalpana J \& Bhushan P. Development and Application of RAPD-SCAR Marker for Identification of Phyllanthus emblica LINN. Biol Pharm Bull. 2006. 29:2313-2316.

Doyle JJ \& Doyle JL. Isolation of plant DNA from fresh tissue. Focus. 1990. 12:13-15. 
Esh AM \& Nasr MI. Molecular Markers for Smut Resistance in Mutated Population of Sugarcane Clone GT-54-9 through Amplified Fragment Length Polymorphism (AFLP). EC Agriculture. 2014. 1:7-14.

FAO. Crop production. Food and Agriculture Organization of the United Nations, retrieved November 2014. 2014.

Garcia AA, Benchimol LL, Barbosa AM, Geraldi IO, Souza Jr CL \& Souza AP. Comparison of RAPD, RFLP, AFLP and SSR markers for diversity studies in tropical maize inbred lines. Genet Mol Biol. 2004. 27:579-588.

Gillaspie AG, Mock RG \& Dean JL. Differentiation of Ustilago scitaminea isolates in Greenhouse Tests. Plant Dis. 1983. 67:373-375.

Heinze BS, Thokoane LN, Williams NJ, Barnes JM \& Rutherford RS. The SmutSugarcane interaction as a model system for the integration of marker discovery and gene isolation. Proc S Arf Sug Technol Ass. 2001. 75:88-93.

Huang N, Zhang YY, Xiao XH, Huang L, Wu QB, Que YX \& Xu LP. Identification of smut-responsive genes in sugarcane using cDNA-SRAP. Genet Mol Res. 2015. 14:6808-6818.

Huckett BI \& Botha FC. Stability and potential use of RAPD markers in a sugarcane genealogy. Euphytica. 1995. 86:117-125.

Jiang S, Jianhua X \& Li X. A Study on the RAPD and SCAR Molecular Markers of Piper Species. J Agric Rural Dev Trop Subtro. 2009. 110:127-135.

Khan HMWA, Chattha AA, Munir M \& Zia A. Evaluation of resistance in sugarcane promising lines against whip smut. Pak J Phytopathol. 2009.21:92-93. 
Krishnamma K, Bhupal JVR \& Ramchandra RB. Evaluation of sugar-cane clones/ varieties for resistance to smut caused by Ustilago scitaminea. Syd. Indian Sug. 1999. 2:31-33.

Li SF, Tang SJ \& Cai WQ. RAPD-SCAR markers for genetically improved NEW GIFT Nile Tilapia (Oreochromis niloticus niloticus L.) and their application in strain identification. Zool Res. 2010. 31:147-153.

Magarey RC, Bull JI, Sheahan T \& Denney D. Yield losses caused by sugarcane smut in several crops in Queensland. Proc Aust Soc Sugar Cane Technol. 2010. 32:347354.

Michelmore RW, Paran I \& Kesseli RV. Identification of markers linked to diseaseresistant genes by bulked segregant analysis: a rapid method to detect markers in specific genomic regions by using segregating populations. Proc Natl Acad Sci. 1991. 88:9828-9832.

Mohan M, Nasir S, Bhagwat A, Krishna TG, Yano M, Bhatia CR \& Sasaki T. Genome mapping, molecular markers and marker-assisted selection in crop plants. Mol Breed. 1997. 3:87-103.

Muhammad K, Afghan S, Pan YB \& Iqbal J. Genetic variability among the brown rust resistant and susceptible genotypes of sugarcane by RAPD technique. Pak J Bot. 2013. 45:163-168.

Muhammad K. Identification and characterization of Rust Resistance Gene (s) in Commercial Cultivars of Sugarcane (Saccharum hybrids L.). PhD thesis. University of the Punjab. Lahore. Pakistan. 2010. 
Paran I \& Michelmore RW. Development of reliable PCR-based markers linked to downy mildew resistance genes in lettuce. Theor Appl Genet. 1993. 85:985-993.

Que Y, Xu L, Wu Q, Liu Y, Ling H, Liu Y, Zhang Y, Guo J, Su Y, Chen J, Wang S \& Zhang C. Genome sequencing of Sporisorium scitamineum provides insights into the pathogenic mechanisms of sugarcane smut. BMC Genomics. 2014. 15:996

Sartorato A, Nietsche S, Barros EG \& Moreira MA. RAPD and SCAR markers linked to resistance gene to angular leaf spot in common beans. Fitopatol Bras. 2000. 25:637-642.

Schenck S. New race of sugarcane smut on Maui. Hawaii Agriculture Research Center Pathology Report 69. 2003.

Souza GM, Berges H, Bocs S, Casu R, D’Hont A, Ferreira JE, Henry R, Ming R, Potier B, Sluys MAV, Vincentz M \& Paterson AH. The sugarcane genome challenge: strategies for sequencing a highly complex genome. Trop Plant Biol. 2011. 4:145156.

Srivastava MK, Li CN \& Li YR. Development of sequence characterized amplified region (SCAR) marker for identifying drought tolerant sugarcane genotypes. Australian J of crop science. 2012. 6:763-767.

Sundar AR, Leanard Barnabas EL, Malathi P \& Viswanathan R. A Mini-Review on Smut Disease of Sugarcane Caused by Sporisorium scitamineum. Botany. 2012. 5:107128.

Wang XH, Yang QH, Li FS, He LL \& He SC. Molecular identification of Saccharum spp.×Erianthus fulvus hybrids using sequence-characterized amplified region markers. Crop Sci. 2009. 49:864-870. 
Williams JGK, Kubelik AR, Livak KJ, Rafalski JA \& Tingey SV. DNA polymorphisms amplified by arbitrary primers are useful as genetic markers. Nucleic Acids Res. 1990. 18:6531-6535.

Wu JM, Li YR, Yang LT, Fang FX, Song HZ, Tang HQ, Wang M \& Weng ML. cDNASCoT: A novel rapid method for analysis of gene differential expression in sugarcane and other plants. Australian J of crop science. 2013. 7:659-664.

$\mathrm{Xu}$ L \& Chen R. Identification of RAPD marker linked to smut resistance gene in Sugarcane. Chin J Appl Environ Biol 2004.10:263-267.

Yang L, Fu S, Khan MA, Zeng W \& Fu J. Molecular cloning and development of RAPDSCAR markers for Dimocarpus longan variety authentication. SpringerPlus. 2013. 2:501.

Zhang W, Yin L, Wei S, Deng Z, YI J, Wu R \& Chen Q. RAPD Marker Conversion into a SCAR Marker for Rapid Identification of Johnsongrass [Sorghum halepense (L.) Pers.]. Not Bot Horti Agrobo. 2013. 41:306. 
1 Tables:

2

3 Table 1

4 A list of sugarcane cultivars with parentage and smut disease response information

\begin{tabular}{ccc}
\hline Cultivar & Parentage & Smut disease reaction \\
\hline CPSG-437 & CP92-1320 × CP92-1167 & R \\
CPSG-3481 & CP85-1308 × CP81-1238 & R \\
CP77-401 & CP66-313 × CP71-400 & MR \\
CPF-237 & 86P-19 × CP70-1133 & MR \\
NSG-59 & 87 2007 × 77Fo790 & MR \\
HoG-315 & CP90-956 × CP89-879 & MR \\
SPSG-26 & SP73-5358 × SP70-1143 & S \\
CSSG-2402 & MG87-1215 × 86A-3626 & S \\
CSSG-668 & 81-N289 × CP74-2005 & MS \\
SPSG-79 & N5679 × SP70-1143 & MS \\
SPF-241 & Polly cross - CP49-34 & MS \\
HoSG-449 & CP88-702 × CP86-1747 & MS \\
\hline Abbreviations: R, Resistant; MR, Moderately resistant; S, Susceptible; MR, Moderately susceptible.
\end{tabular}

6 
Table 2

11 A list of sugarcane cultivars used in marker validation experiments.

\begin{tabular}{cc}
\hline Nomenclature & Smut disease reaction \\
\hline CPF-251 & HR \\
HoTh-1821 & $\mathrm{R}$ \\
CPF-252 & $\mathrm{R}$ \\
CPF-249 & $\mathrm{R}$ \\
CSSG-32 & $\mathrm{MR}$ \\
HSF-240 & $\mathrm{MR}$ \\
\end{tabular}

12 Abbreviations: HR, Highly resistant; R, Resistant; MR, Moderately resistant; S, Susceptible; MR, Moderately

13 susceptible.

14

15

16

17

18

19

20

21

22

23

24

25

26 


\section{Figures:}

2

$3 \quad$ Figure 1, Figure 4, Figure 5 and Figure 7 are Single column fitting.

$4 \quad$ - Figure 2, Figure 3 and Figure 6 are 1.5 column fitting.

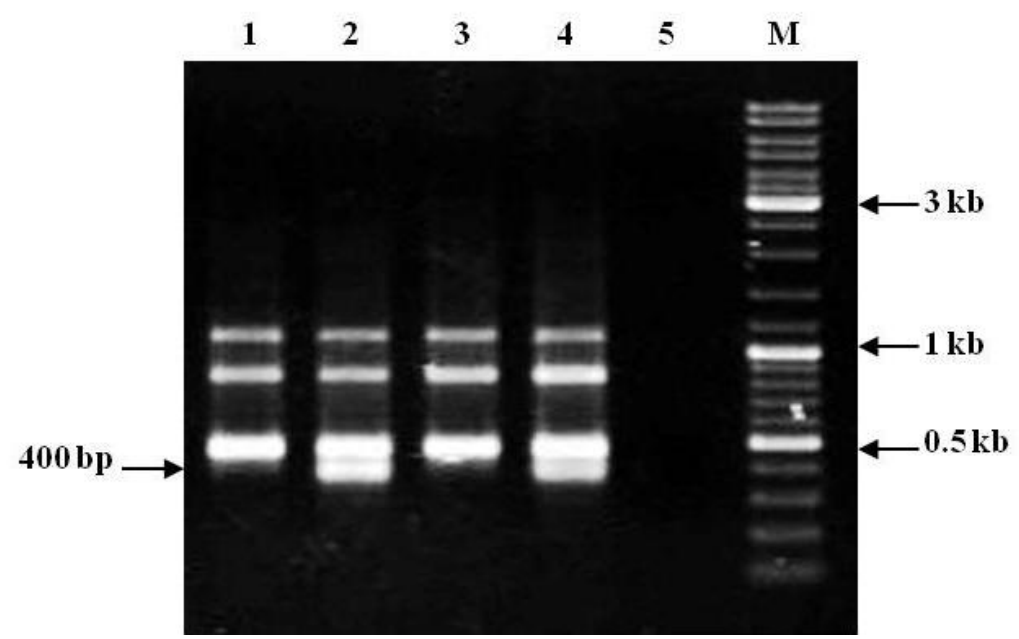

7 Fig. 1. Ethidium bromide-stained RAPD products of primer B17 from four sugarcane DNA

8 bulks in 1\% agarose gel. Lanes 1 and 2: completely resistant and completely susceptible bulks,

9 respectively; Lanes 3 and 4: moderately resistant and moderately susceptible bulks, respectively;

10 Lane 5: negative control; and M: DNA ladder Mix (Fermentas cat\#SM0331). 


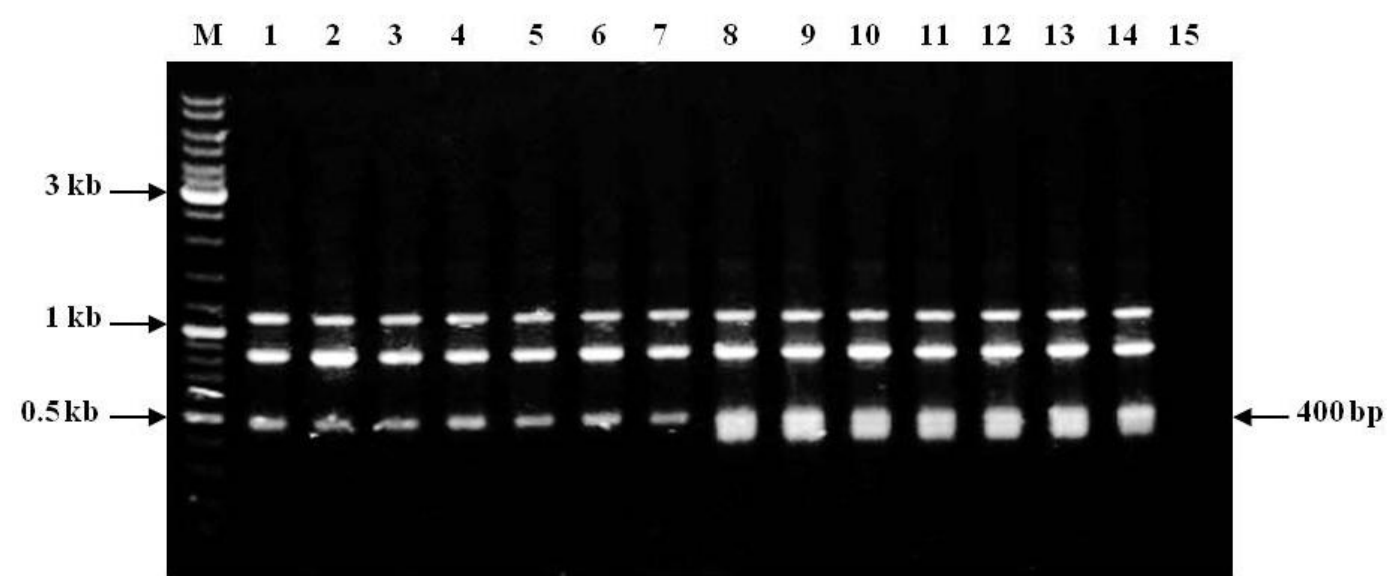

17 Fig. 2. Ethidium bromide-stained RAPD products of primer B17 from 12 sugarcane cultivars

18 and two bulked DNA samples in 1\% Agarose gel electrophoresis. M: DNA ladder Mix

19 (Fermentas cat\#SM0331); Lane 1: resistant DNA bulk; Lanes 2-7: sugarcane cultivars, either

20 completely resistant to smut (CPSG-437 and CPSG-348) or moderately resistant to smut (CP77-

21 401, CPF-237, NSG-59 and HoG-315), respectively; Lane 8: susceptible DNA bulk; Lanes 9-14:

22 sugarcane cultivars, either completely susceptible to smut (SPSG-26 and CSSG-2402) or

23 moderately susceptible to smut (CSSG-668, SPSG-79, SPF-241 and HoSG-449), respectively;

24 and Lane 15: negative control containing only water.

25

26

27

28

29

30

31

32 


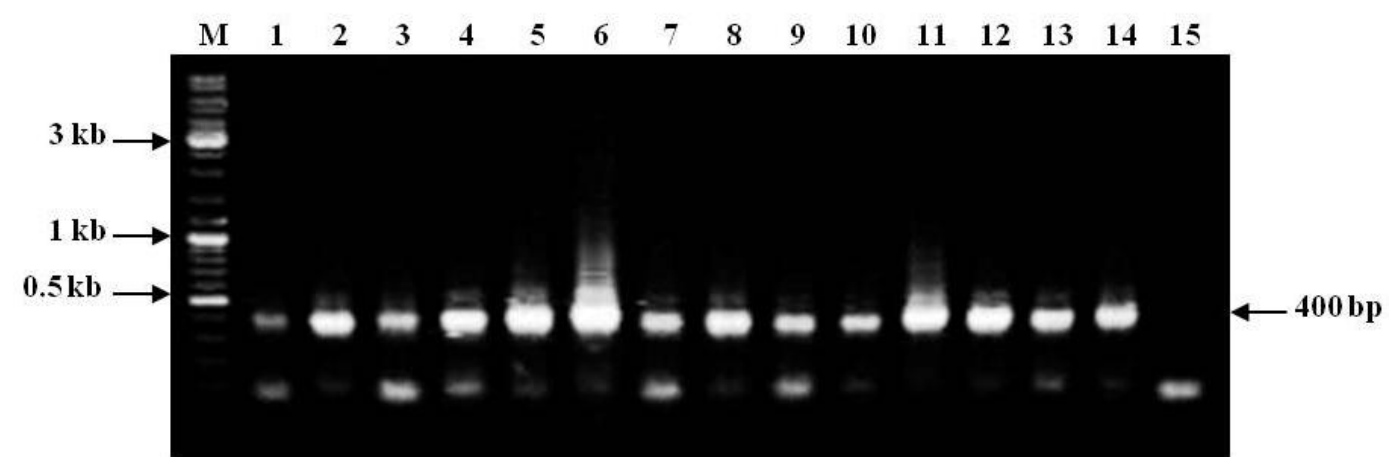

Fig. 3. Analysis of B1-F/B1-R SCAR marker on 12 smut resistant and susceptible sugarcane

35 cultivars and their respective bulks by PCR and 1\% agarose gel electrophoresis. M: DNA ladder 36 Mix (Fermentas cat\#SM0331); Lane 1: DNA bulk of smut resistant cultivars; Lanes 2-7: Six

37 cultivars, two completely resistant (CPSG-437 and CPSG-348) and four moderately resistant

38 (CP77-401, CPF-237, NSG-59, and HoG-315); Lane 8: DNA bulk of smut susceptible cultivars;

39 Lanes 9-14: six cultivars, two completely susceptible (SPSG-26 and CSSG-2402) and four

40 moderately susceptible (CSSG-668, SPSG-79, SPF-241, and HoSG-449); and Lane 15: negative

41 control containing water only. 


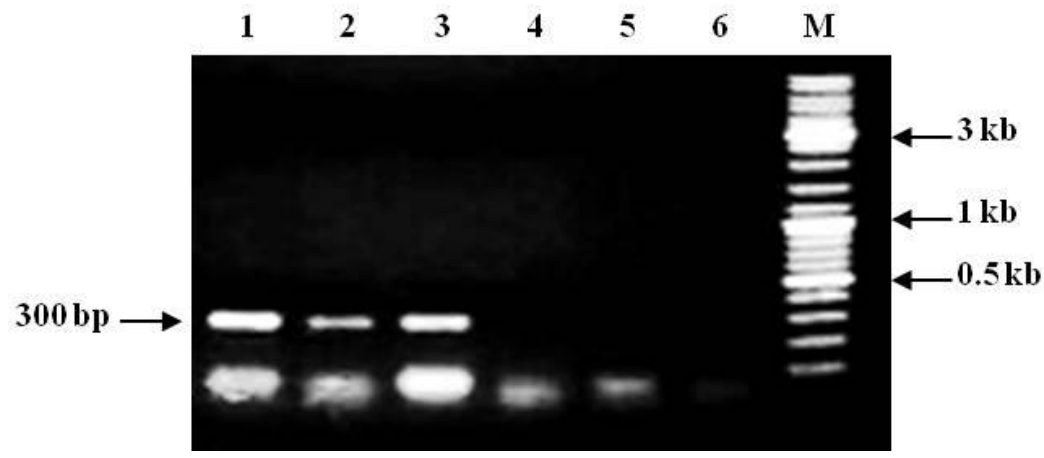

52 Fig. 4. Testing of the B1SM-F/B1SM-R SCAR marker on four sugarcane cultivars (completely

53 resistant and completely susceptible to smut disease) along with their respective DNA bulk

54 samples by PCR and 1\% agarose gel electrophoresis. Lane 1: DNA bulk of completely resistant

55 cultivars; Lanes 2 and 3: two completely resistant cultivars (CPSG-437 and CPSG-3481); Lane

56 4: DNA bulk of completely susceptible cultivars; Lanes 5 and 6: two completely susceptible

57 cultivars (SPSG-26 and CSSG-2402); and M: ladder Mix (Fermentas cat\#SM0331). 


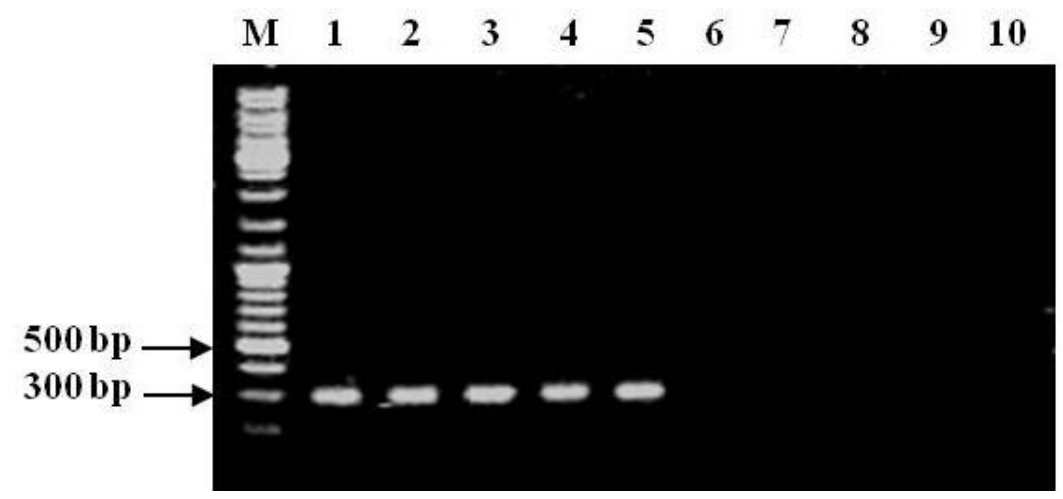

Fig. 5. Testing of the B1SM-F/B1SM-R SCAR marker on eight sugarcane cultivars (moderately

70 resistant and moderately susceptible to smut disease) along with their respective DNA bulk samples by

71 PCR and 1\% agarose gel electrophoresis. M: ladder Mix (Fermentas cat\#SM0331); Lane 1: DNA bulk

72 of moderately resistant cultivars; Lanes 2-5: four moderately resistant cultivars (CP77-401, CPF-237,

73 NSG-59, and HoG-315); Lane 6: DNA bulk of moderately susceptible cultivars; and Lanes 7-10: four

74 moderately susceptible cultivars (CSSG-668, SPSG-79, SPF-241, and HoSG-449).

75

76

77

78

79

80

81

82 
IGAGA A TA T TAG T CA T G C T G T G C A A A A A Majority $91 \frac{100}{1} \frac{110}{120} 1$ T A A A T A A T T A G T C A T G C T G T G C A A A A A C B17-resistant $89 \ldots \ldots$ I I A G G C A I G C I A T G C A A A A-C C B17-susceptible

84 Fig. 6. Nucleotide sequence alignment of B1SM-R primer site derived from reverse-

85 complementary sequences of one representative B1-F/B1-R SCAR fragment from the resistant

86 cultivars and one representative B1-F/B1-R SCAR fragment from susceptible cultivars.

87

88

89

90

91

92

93

94

95

96

97

98

99

100

101

102 


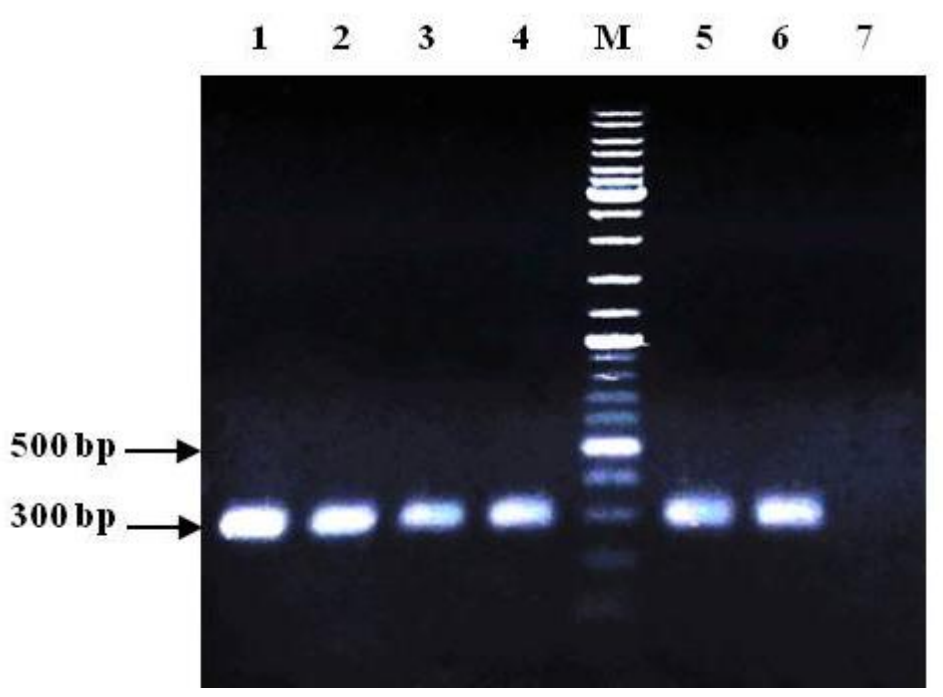

104 Fig. 7. Validation of the B1SM-F/B1SM-R SCAR marker on seven Pakistani sugarcane cultivars 105 by PCR and 1\% agarose gel electrophoresis. Lane 1: HoSG-31, highly resistant to smut; Lanes 2106 4: CPF-251, HoTh-1821, and CPF-252, completely resistant to smut; M: DNA ladder Mix 107 (Fermentas cat\#SM0331); Lanes 5 and 6: CPF-249 and CSSG-32, moderately resistant to smut; 108 and Lane 7: HSF-240, moderately susceptible to smut. 